\title{
The TUM Accessibility Atlas: Visualizing Spatial and Socioeconomic Disparities in Accessibility to Support Regional Land-Use and Transport Planning
}

\author{
Benjamin Büttner $^{1}$ (D) Julia Kinigadner ${ }^{1}$. \\ Chenyi $\mathbf{J i}^{1}$ • Benjamin Wright ${ }^{1}$. \\ Gebhard Wulfhorst ${ }^{1}$
}

(C) The Author(s) 2018. This article is an open access publication

\begin{abstract}
In recent years, the city of Munich has become more crowded due to its strong job market and its popularity as a tourist destination, resulting in a shortage of affordable housing and a strained transport network. It became evident that the city of Munich could not solve these problems alone, and would need close cooperation with neighboring municipalities that considered the various stakeholders. In 2007, this resulted in the formation of the Metropolitan Region of Munich, home to nearly six million people from 27 counties and 6 large cities, and includes 158 participating institutions. In 2009, the TUM Accessibility Atlas was developed for this newly formed region after numerous discussions with a variety of regional stakeholders who described their needs in assessing land-use and transport measures. The major task of this tool was to meet these needs and support this diverse region find a common regional identity.
\end{abstract}

Keywords Accessibility · Accessibility instruments · PSS · Governance · Decisionmaking $\cdot$ Accessibility planning

The TUM Accessibility Atlas brings together various scientific measures of accessibility that have been developed over time and applies them to relevant issues in the field of integrated land use and transport planning. The primary usability issue addressed by this tool is the need for more trust and a shared language between stakeholders. The main planning issue is determining how the region can improve multimodal

Benjamin Büttner

benjamin.buettner@tum.de

1 Chair of Urban Structure and Transport Planning, Technical University of Munich, Arcisstr. 21, 80333 Munich, Germany 
accessibility, becoming more environmentally sustainable while also identifying spatial and socioeconomic disparities to address.

Given these purposes, the TUM Accessibility Atlas was set up as a GIS toolbox, capable of producing maps for specific case studies and their thematic issues. The two major datasets are a multi-modal transport network and the structural land-use layers. The public transport network is based on a VISUM transport model imported into a GIS based accessibility instrument. Initially, the street network was initially provided by the Bavarian State Office for Statistics and Data Processing, but later substituted by OpenStreetMap (OSM), due to the flexibility of the open source data and the greater detail available for non-motorized transport modes. The structural component was provided by numerous sources (e.g. gaining suitable data by web survey) which included geo-referenced data on activities and their respective densities. These datasets have been constantly updated and upgraded in line with the current issues of different areas. Over the course of various research projects, new scales and suitable add-on tools have been added. To help visualize spatial and socioeconomic disparities, the TUM Accessibility Atlas has explored the relative accessibility of the region by public vs private transport, mismatches between the population density and public transport service quality, and the vulnerability of the region to future increases in mobility costs. Different methods and scales have been integrated: from micro-scale accessibility within neighborhoods to macro-scale regional accessibility to jobs. These accessibility indicators have been developed and tested within multi-stakeholder workshops. Findings have shown that clear visualization of spatial and socio-economic disparities helps guide discussions between multiple stakeholders, helping to develop common solutions as part of a sound planning process.

Current and future research directions will transform the TUM Accessibility Atlas into a more flexible and dynamic planning instrument, and make it available online. The ability to analyze $\mathrm{CO} 2$ emissions based on the location and travel modes is being implemented. Lessons from using the TUM Accessibility Atlas have shown such that successful instruments should feature high quality, up-to-date data from various sources, active participation and support from stakeholders, and the use of clear and transparent indicators. Visualizing accessibility and the associated spatial and socioeconomic disparities have proven to be especially effective in supporting and steering regional land-use and transport planning.

\section{Introduction}

\subsection{The Metropolitan Region of Munich and its Challenges}

The metropolitan region of Munich includes 6 urban districts (cities) and 27 rural districts (counties) with an area of $26,000 \mathrm{~km}^{2}$ and is home to six million inhabitants as of 2015. The population increased by around $20 \%$ from 1990 to 2015 , while the unemployment rate was only $3.4 \%$ (in comparison to $6.1 \%$ in Germany) in 2016 (Metropolregion München 2016).

Munich's exceptionally strong labor market and its appeal as a tourist destination has caused the city to consistently rise in popularity. The new residents and need for additional tourist accommodation has resulted in a shortage of affordable housing 
and increasing strain on the transport network due to the extra demand. It has become evident that the city of Munich will not be able to solve its problems all by itself, but will have to collaborate with partners in the region. This led to the formation of the Metropolitan Region of Munich (German: EMM Europäische Metropolregion München) in 2007. The EMM aims to enable closer cooperation, better dialogue, and a jointly developed vision for the future among its constituent cities and counties, as well as 158 partner institutions that range from economic organizations and NGOs to education and science partners (Reiss-Schmidt 2014).

The region faces several challenges in the future as it expects to add up to 500,000 new residents by 2030, according to Wolfgang Wittmann, director of the EMM (Metropolregion München 2016). This growth, while beneficial for the economy, also has consequences. In the last five years, the costs of buying a home in the region have risen 9 to $33 \%$ and rental costs have risen 5 to $18 \%$, with the largest increases being in the city of Munich (München 2014). As living costs increase, people often move farther away and face longer commutes (Büttner et al. 2014). Commuting distances in the metropolitan region are already higher than the German average ( $17.1 \mathrm{vs} 16.3 \mathrm{~km}$ ) and continue to increase as the number of commuters coming from outside Munich's public transport region increases faster than those coming from within (Reiss-Schmidt 2014).

There was a clear need for an instrument to analyze the issues posed by increases in population, living costs, and commuting distances. Based on the motivation by selected stakeholders and the initiative of the university, the TUM Accessibility Atlas was established in 2009 as a resource for the metropolitan region. These stakeholders emphasized the need to assess land-use and transport measures, and the need for this diverse region to develop a shared regional identity. The 'TUM Accessibility Atlas' was thus conceived and subsequently developed as a strategic instrument for analysis and planning (Büttner et al. 2010). With clear and transparent visualizations that target a common understanding between all stakeholders, the TUM Accessibility Atlas aims to investigate, understand and visualize the potential and risks of land-use and transport development on a local level in order to improve regional governance and decision-making processes. The concept of accessibility was chosen as the most effective way to measure these impacts and achieve these improvements.

\subsection{Objective, Research Questions, and Structure of the Paper}

The objective of this paper is to highlight how accessibility instruments such as the TUM Accessibility Atlas can help to produce effective land-use and transport strategies. Sustainable regional development comprises a social, economic, and ecological dimension (Wegener and Fürst 1999). The land-use and transport system should be designed in a way that fosters economic prosperity and ensures equal access to opportunities for social interaction. At the same time, sustainable development needs to minimize negative impacts on the environment. Based on this overarching principle, a large variety of specific planning objectives can be defined. In order to be useful for many different planning issues, accessibility instruments need to be flexible with respect to the basic elements of accessibility, specified by Reggiani and Martín (2011) as: study area, transport network, economic 
activities, and economic actors. This raises the question of how various accessibilityrelated datasets can be combined in different ways to create tailored solutions for a variety of planning tasks.

The TUM Accessibility Atlas serves as an example for a platform combining different datasets, transport modes, and accessibility measures on various scales. Three applications of the tool are described in this paper, each representing a different research question. The first research question was how to reduce car dependency in the region, improving its environmental and social sustainability. The tool was therefore used to map the region's relative accessibility to jobs by private and public transport, identifying disparities and areas where public transport could be improved to be more competitive with the private car. The second research question was how to achieve better integration of land-use and transport. The tool was used to identify locations with high accessibility and locations with high activity density, with areas of mismatch between the two showing a need for either higher density or better accessibility. The final research question was how to reduce the region's vulnerability to shocks in gasoline prices. Here, the tool was used to map spatial and socioeconomic disparities in private car use, income, and accessibility with alternative transport modes, highlighting the most vulnerable areas to price shocks and the need to reduce injustice.

This paper is organized as follows: Chapter 2 provides a literature review of accessibility definitions, measures and instruments, and explains the need to measure inequalities in accessibility. Chapter 3 first introduces the TUM Accessibility Atlas as a successful instrument to measure and visualize inequalities (section 3.1), then proceeds through various applications which cover the three research questions of competition between public transport and private transport (section 3.2), imbalances between accessibility and land-use (section 3.3), and vulnerability to gasoline price increases (section 3.4). The applications of the tool mentioned in this paper represent only a small portion of the potential planning tasks. Therefore, Chapter 4 discusses the ongoing and future development of this instrument's applications. Finally, Chapter 5 summarizes the paper with some concluding thoughts about the TUM Accessibility Atlas.

\section{Accessibility in Spatial Planning}

\subsection{Definitions and Measures of Accessibility}

The utilization of accessibility in spatial planning requires a common understanding of the concept. Many definitions refer to accessibility as a potential (Hansen 1959; Páez et al. 2012; Papa and Bertolini 2015) that increases with the number or attractiveness of opportunities available (Bertolini et al. 2005; Handy and Niemeier 1997). The spatial separation between opportunities requires a transport system enabling travel to different locations (Dalvi and Martin 1976; Morris et al. 1979). Thus, accessibility considers transport as well as land-use aspects, which differentiates it from mobility (Koenig 1980). Geurs and van Wee (2004) add two further aspects: an individual component, which considers characteristics and abilities of individuals, and a temporal component, describing time-based constraints. 
Researchers have developed a number of indicators in search of a quantitative measure to express accessibility (Geurs and Ritsema van Eck 2001; Geurs and van Wee 2004; Handy and Niemeier 1997). While the most accurate depiction might require all four aspects mentioned above, usually only a subset is considered in order to reduce data requirements and complexity. Location-based accessibility measures, focusing on the land-use and transport dimensions, count among the most frequently used ones, as the required data is readily available (Geurs and van Wee 2004; Handy and Niemeier 1997). Person-based or activity-based indicators, on the contrary, require disaggregate data on an individual level (Dong et al. 2006). They are able to better depict differences in accessibility levels among individuals, but are less suitable for aggregate analyses on smaller scales (Geurs and van Wee 2004; Handy and Niemeier 1997). For this reason, the TUM Accessibility Atlas utilizes the following locationbased accessibility measure for analyses on the scale of the metropolitan region of Munich:

$$
A i=\sum_{j=1}^{n} D_{j} f\left(c_{i j}\right)
$$

where $A_{i}$ is the accessibility of location $i$ to all destinations $n$ and $D_{j}$ is the destination potential at location $\mathrm{j}$. The destination potential is multiplied by a function of $\mathrm{c}_{\mathrm{ij}}$, which measures the costs for overcoming the spatial separation between origin $i$ and destination $\mathrm{j}$. Thus, the sum of accessibilities to all destinations $\mathrm{n}$ results in the total accessibility of location i.

Different categories of destination potentials like shopping facilities, leisure activities, population or employment can be considered. Employment is one of the most commonly used categories, often with a focus on equity issues (Cheng and Bertolini 2013; Hu 2014; Wang 2000). The costs for travelling from origin to destination are usually expressed in terms of travel time, although distance, comfort, monetary travel costs, or a combination of indicators can be considered as well. The cost function can also be formulated in different ways. Contour measures or cumulative opportunity measures use a step function, which equals 1 within a certain travel cost threshold and drops to 0 after the threshold is surpassed. As a result, only destinations inside the catchment area will contribute to the total accessibility $\mathrm{A}_{\mathrm{i}}$. Thus, contour measures are easy to use and understand. However, their strict cut-off value with no further differentiation between destinations within the catchment area results in low measurement accuracy (Cheng and Bertolini 2013; Bertolini et al. 2005). Gravity-based measures try to overcome this methodological weakness by utilizing a continuous distance-decay function. The form and parameters of the function should be chosen according to empirical travel data from the study area (Geurs and van Wee 2004). For an early example, using the inverse of travel time and travel distance, see Hansen (1959). More recent applications use a negative power function or a negative exponential function (Reggiani et al. 2011a, b). The exponential decay is more appropriate for analysing short distance interactions within a relatively homogeneous urban area, while the power decay is more appropriate for long distance interactions, such as migration flows between metropolitan areas (Fotheringham and O'Kelly 1989: 12-13). Handy and Niemeier (1997) state that the exponential function is most frequently used due to its close ties to travel behavior theory. Therefore, the exponential form was implemented 
by the TUM Accessibility Atlas for the relative accessibility analysis described in section 3.2 .

$$
A_{i}=\sum_{j=1}^{n} D_{j} e^{-\beta c_{i j}}
$$

Equation (2) is a modification of Eq. (1), implementing an exponential distance decay as the travel cost function. The parameter $\beta$ represents the travel cost elasticity, describing how sensitive people are to variations in travel costs. This parameter has a negative sign, as the probability a certain location is chosen as destination drops with each additional minute of travel time. The value of $\beta$ may vary depending on mode or household type and is usually calibrated based on survey data (Geurs and van Wee 2004; Cheng and Bertolini 2013; Reggiani et al. 2011a).

\subsection{Need for Measuring Spatial and Socioeconomic Inequality of Accessibility}

When proper measurements are used, accessibility analyses are able to identify spatial or socioeconomic disparities and provide a basis for decision-making in planning practice. The need to reduce inequality in accessibility is based on the principle that people who do not have access to a car should still be able to reach important destinations like workplaces (Sanchez et al. 2004). Negative effects of transport activities, for example emissions or the consumption of scarce resources, are primarily a result of intensive car use (Wegener and Furst, 1999). Therefore, accessibility improvements by alternative modes do not only have positive social, but also environmental effects. With this perspective, evaluating spatial and socioeconomic inequality is a key component of successful accessibility planning.

There also tends to be a cause-and-effect relationship where spatial disparities in accessibility create socioeconomic disparities. Many studies have found that improvements in the accessibility by any mode are correlated with increases in property value. For instance, de Graaff et al. (2012), Bina et al. (2006), and Cortright (2009) show that home value increases are positively correlated with increases in rail, private car, and walking accessibility respectively. Better accessibility makes neighborhoods more desirable to live in since it is easier to commute to work, run errands, and make discretionary trips. However, the higher home values from better accessibility tend to gradually attract wealthier residents and push out poorer residents, creating problems such as the shortage of affordable housing observed in Munich (Büttner et al. 2016; Büttner 2017).

Socioeconomic differences also create differences in accessibility needs. They influence the length of commutes as minorities and those with low income or education typically commute farther and are less likely to work from home than high-income and well-educated groups (Huber 2014). Trip rates also vary by income, such that those with less disposable income make fewer trips on average. In the United States, the 2009 National Household Travel Survey showed that households make about 5.8 person-trips per day if their annual income is below $\$ 10,000$ and this steadily rises with income, up to 13.2 person-trips per day for annual incomes above $\$ 80,000$. Di Paolo et al. (2017) state that those that are 
better educated are more at risk of job-education mismatch but that better accessibility by private car and public transport both reduce the rate of mismatch, especially for females. However, the most notable effect that is observed is that households with lower incomes are less likely to drive alone and more likely to use public transport (AASHTO 2013). Therefore, the most effective way to balance accessibility across socioeconomic groups is to provide accessibility by public transport and non-motorized modes that is competitive with that by private car. In trying to tackle this issue, many existing studies focus on the comparison between accessibility by public transport and accessibility by car (see for example Benenson et al. 2011 or Hess 2005). This focus has also been applied by the TUM Accessibility Atlas (see section 3.2). Overall, once socioeconomic disparities have been created, they affect the accessibility needs of the area. Therefore, these differences must be identified before developing policies to improve accessibility.

It is important to note that policies to improve and balance accessibility are highly dependent on subjective values, especially in public transport. For example, Manaugh and El-Geneidy (2012) evaluates whether public transport projects in Montreal improve accessibility to low-skilled jobs at least as much as overall job accessibility. Walker (2012) calls attention to a decision of whether to improve public transport accessibility in a way that increases ridership (based on the idea that service should consider profitability) or that increases coverage (with the idea that public transport is a basic social need that everyone deserves access to). In practice, municipalities have policies for both private and public transport that combine many different accessibility goals; the improvement of spatial and socioeconomic disparities is just one aspect of a complex decision making process. Therefore, a robust tool that helps visualize accessibility disparities in a clear and simple way can help improve the efficiency and transparency of the overall process.

\subsection{Accessibility Models for Integrated Land-Use and Transport Planning}

Accessibility is not only suitable for evaluating inequalities, but can also assess the efficiency of the land-use and transport system in enabling individuals to reach destinations (Geurs and van Wee 2004). Certain qualities of the urban structure (density, diversity) and the transport system (connectivity, design) benefit accessibility (van Wee 2011). However, as highlighted by Papa and Bertolini (2015), the variable with the greatest impact on accessibility is the distribution of dense urban structures in relation to the transport network, i.e. the degree of integration between land-use and transport.

Transit-oriented development is a dominant theme in integrated land use and transport planning (Calthorpe 1993; Cervero et al. 2002; Papa and Bertolini 2015). Cervero (1998) finds that public transport use is highest where urban structure and public transport infrastructure have adapted to each other. In order to increase the match between land-use and transport, tools and models have been developed that highlight the potential for more intensive land-use at highly accessible nodes as well as the need for improvements of the public transport system at dense locations. Bertolini's (1999) node-place model evaluates the public transport quality of a node (node value), as well as the diversity of activities around it (place value). Mismatches between the node and 
place values highlight the need for active intervention (Reusser et al. 2008) or help to understand development dynamics (Chorus and Bertolini 2011).

The land use and public transport accessibility index (LUPTAI) is also able to direct planning decisions towards better integration of land-use and transport (Pitot et al. 2006). Like the node-place model, the LUPTAI optimizes the match between two variables, namely the land-use density and the public transport accessibility. Suggestions for accessibility improvements and land-use changes can be visualized in maps and these models can then provide an easy interpretation of the outcomes, making them highly suitable for integrated land-use and transport planning. The principle of balancing the land-use and transport systems, represented by these two indicators, is highly flexible and can be adapted for different spatial scales and thematic contexts. Section 3.3 highlights how the LUPTAI can be applied to derive strategies for a better integration between land-use and transport on the county level.

\subsection{Vulnerability as a Way to Model Disparities in Accessibility}

One way to model the spatial and socioeconomic disparities in accessibility is to show which locations and which people are most affected by external factors that impact their accessibility. Vulnerability is an especially useful term to express and analyze the impact of these external factors. The term was first applied in the eA arly 1980s as a socioeconomic concept by economics Nobel laureate Amartya Sen to study hunger catastrophes, highlighting the need for measures to guard against food shortages and political action in support of sustainability and protection of the food supply (Sen 1999). One common definition of vulnerability is "the degree to which a system is likely to experience harm due to exposure to a hazard" (Turner et al. 2003). However, specific measures are needed that can quantify the degree of vulnerability.

Kasperson et al. (2006) recognizes three dimensions that characterize vulnerability to stresses or shocks: exposure, sensitivity, and resilience. Here, exposure refers to the 'dose' of the stress, sensitivity refers to the capacity to absorb the dose, and resilience refers to the ability to adapt and thereby reduce the impact of the stress. While resilience can be thought of as a component of vulnerability, it can also be considered separately since it focuses specifically on the recovery from a stress or shock. According to Rose (2009, p. 3).

Vulnerability is predominantly a pre-disaster condition, but that resilience is the outcome of a post-disaster response. A number of studies have already looked at the vulnerability and resilience of transport networks from various perspectives (Caschili et al. 2015). For example, Chen et al. (2007) examines the vulnerability of transport networks when a certain link fails by considering the impacts on individuals' choice of trip, mode, and route and then calculating the new accessibility of the overall network. Cats and Jenelius (2014) models the vulnerability of public transport networks to service disruptions and the degree to which real-time information can improve resilience. In section 3.4, the TUM Accessibility Atlas extends the concept of vulnerability, specifically the dimensions of vulnerability described by Kasperson et al. (2006), to study the impact of gasoline price shocks on mobility. In this application, resilience is considered as a component of vulnerability, where better accessibility to jobs improves resilience and reduces the vulnerability of a region. 


\subsection{Suitability of Accessibility Instruments for Planning Practice}

As highlighted in this section, there are many different possibilities to use accessibility as a concept in planning practice. Accessibility instruments should incorporate indicators and processes that are easy to understand and use, but they also need to depict the system realistically and transparently (Bertolini et al. 2005; Cheng and Bertolini 2013). The tools will only be able to contribute to a common language among stakeholders and better planning outcomes if these requirements are fulfilled. A recent study te Brömmelstroet et al. (2017) confirms that a lack of trust and understanding among different stakeholders involved in transport planning is a barrier to usability. Planning support systems need to consider and tackle these issues in order to contribute to decision-making processes. The TUM Accessibility Atlas is one successful example for achieving a compromise between these different requirements. Specific examples related to the needs of the metropolitan region of Munich (section 1.1) and the research questions of this paper (section 1.2) are presented in the following chapter.

\section{Applying the TUM Accessibility Atlas to Measure and Visualize Inequalities}

\subsection{Design of the TUM Accessibility Atlas}

The TUM Accessibility Atlas was first brought to life within the project "An Accessibility Atlas for the European Metropolitan Region of Munich". The main objective of the project was the creation of a computer-based tool to perform practical accessibility analyses in the EMM region using scientifically-supported methods, and thereby helping to shape the future mobility in the area (Büttner et al. 2010; Büttner et al. 2011). This tool is primarily a database of structural (population, employed people, motorization, etc.) and transport supply (road networks with relevant attributes, public transport stop and line model with timetables) datasets that cover the geographic area of the European Metropolitan Region of Munich (EMM). In Germany, these structural datasets are publicly available from the statistical administration of the German states with a spatial resolution of municipalities, and a further differentiation at the city borough level for the largest cities (i.e., Munich, Augsburg and Ingolstadt in the EMM region). To arrive at a more detailed level of structural data, disaggregation methods based on land-use density estimations are used. This is currently done by using CORINE Land Cover data and land use data if available, but can be refined by additional datasets. Table 1 (see Appendix) provides an overview of the datasets integrated in the TUM Accessibility Atlas for the selected projects.

\subsubsection{Zoning Model of the EMM Region}

At the time of these applications, there were 6 urban districts (cities) and 24 rural districts (counties) as members of the EMM region (now there are 6 cities and 27 counties). Moreover, in order to reduce the boundary problem, 20 adjacent counties 
were also added to the study area of EMM. ${ }^{1}$ Next, the region was divided into zones at the municipality level. The municipality level is a compromise that ensures adequate accuracy of spatial analysis at the regional level of the EMM, as well as excellent data availability. For these municipalities, various statistical data is available and updated regularly by the Federal Statistical Office. The requirements, reliability, and "external updates" necessary for the data are completely fulfilled. However, a disadvantage of using the municipalities as the resolution of zones is the difference in size and population. In order to avoid exceptional variations, the large cities in the EMM are divided into boroughs. For example, 25 statistical boroughs are used for the city of Munich. However, the official boroughs of the cities of Ingolstadt and Augsburg are too small, and must be aggregated into groups of three and six boroughs respectively. With regard to the division of zones, these boroughs are thus at the same hierarchy level as the other municipalities.

\subsection{Reducing Car Dependence: Regional Accessibility Analysis Comparing Private and Public Transport}

In this application, a comparative analysis of accessibility by private and public transport is used to help develop strategies tackling car dependency, fostering a competitive public transport system, and thus ensuring social and environmental sustainability (see section 2.2).

The accessibility database is mainly built on the software platform ESRI ArcGIS, containing all spatial structural data as well as the transport supply data of private transport. One exception is the public transport model which is created using VISUM Traffic Model Platform by the company PTV AG. The gravity-based accessibility indicators are calculated in Microsoft Excel using travel times and data on population and jobs before being imported to ArcGIS.

\subsubsection{Calculating Travel Time by Public Transport}

Travel times between all the municipalities within the EMM region by both private and public transport were chosen as indicators of the travel cost $c_{i j}$ (see section 2.1). The travel time of public transport is calculated based on the timetable database provided by the Bavarian Railroad Company (Bayerische Eisenbahngesellschaft, BEG). This is HAFAS (HaCon Fahrplan-Auskunfts-System) data from the period of November 2008 to July 2009. Since there are several local public transport associations within the EMM region that each update the HAFAS data at varying intervals, the data could not be collected over a narrower period of time. The data includes long-distance trains, as well as road- and rail-bound public transport.

Due to the fact that ArcGIS does not offer corresponding algorithms for analyzing the timetable data of the public transport, the software PTV VISUM was used for this purpose, as it contains a standard module for routing search in public transport networks. HAFAS data can be read directly into VISUM via a special module.

\footnotetext{
${ }^{1}$ The county of Erding has decided not to be a member of the EMM region, however due to its geographically important role within the region, all datasets and analyses have included the county of Erding.
} 
The goal is to calculate the travel time by public transport from each municipality to all others. However there are usually multiple public transport stops in a municipality. Thus, a representative stop within each municipality is selected. This was the stop with the highest quality of public transport supply and its quality was taken as representative of the connection quality by public transport of the whole municipality. The quality of public transport refers to the importance of the stop: the average travel time to all other stops; the average number of transfers to other lines; and the average service frequency at the stop (see section 3.3). This assumption is based on the idea that small-scale differences in accessibility are determined in the course of the local accessibility analysis, but can be initially disregarded at the regional level.

The result of the calculation is exported as a matrix, with each row representing the "from stop" and each column representing the "to stop". The value of each cell is the travel time by public transport from one stop to another. If there is no connection between two stops, the value of travel time is stored as 999,999 to approximate infinitive impedance.

\subsubsection{Identifying Density Centers in each Municipality}

For the public transport, each municipality is represented by one public transport stop. Similarly, for the private transport, each municipality is represented by the density center, since the zoning model does not fully represent the population distribution or urbanization within the municipalities. In the EMM region, some municipalities are very large in size with regard to the zoning model while the populated area is concentrated at only certain locations within the municipalities. This means that the geometrical centers of the municipalities do not necessarily represent the centers of the populated or urbanized area. CORINE Land Cover (CLC) data is applied in this case to better represent the density centers.

The CLC data are satellite images in which different categories of land surfaces (i.e. agricultural areas, forestry areas, lakes and oceans, urban areas, etc.) can be distinguished. CLC data of the categories representing the built-up area are filtered and converted to a shapefile polygon feature and matched to each municipality. The geometrical center of the CLC polygon of urbanized area in each municipality is defined as the density center of that municipality. If there is no CLC data for the built-up area within the municipality, the geometrical center of the municipality is defined as the density center.

\subsubsection{Modeling the Road Network and Calculating Travel Time for Private Transport}

The travel time by private transport was originally acquired from the data from Federal Institute for Research on Building, Urban Affairs and Spatial Development (BBSR). Later on, private transport travel times were calculated by modeling the private transport road network with crowdsourced data from OpenStreetMap (OSM), which is easy to access and frequently updated. The OSM data downloaded from Geofabrik is already in shapefile format so that it can be directly read into ArcGIS environment.

The first step to model the road network is to remove street links that are not usable by motorized vehicles. Second, the length and speed limit of each street link is 
assigned. The OSM data provides information on the speed limit of each street link which is stored in the attribute "maxspeed". However, not every link has a value for speed limit due to the open source nature of OSM data. Therefore the OSM data must be modified to ensure every link has a speed value so that the calculation of travel time is possible. The travel time is then calculated and stored in a newly created attribute "time" in the road network shapefile. Third, to set up a dataset which is capable of network analysis (e.g. routing from one point to another), an ArcGIS Network Dataset is created from the motorized network, in which the attribute "time" is used as "cost" in the settings. With the Network Dataset and the density centers, the travel time from each municipality (represented by the density center) to every other municipality can be calculated using the Network Analyst in ArcGIS. The travel time by private transport, similar to that of the public transport, are stored as a matrix in an Excel worksheet, in which the rows represent the origin municipality while the columns represent the destination municipality.

To check the quality of the travel times, the results from the OSM network are compared to the results from NAVTEQ. A correlation analysis was performed for 75 randomly selected origin-destination relations within the EMM. There is a correlation coefficient of 0.993 , indicating that the OSM network provides quite good travel time estimates. However, the results of the correlation analysis also indicated that some subareas (for example, the urban area of Munich) show noticeably greater deviations. Here, in-depth analyses are necessary to improve travel times. In principle, these initial results show that the OSM network is suitable for the analysis of accessibility by private transport.

\subsubsection{Modeling Accessibility to Population and Jobs}

The accessibility to population and jobs is determined by a gravity model using an exponential distance decay function as described in section 2.1. The municipal-level population and employment data (destination potential $D_{j}$ ) is exported to Excel from the GENESIS-Online Database of the Federal Statistical Office. The travel times of public and private transport (travel costs $\mathrm{c}_{\mathrm{ij}}$ ) are already calculated and stored in Excel format as documented above. A distance decay parameter $\beta$ of 0.0384 was used for both public and private transport, calibrated by assuming that a potential located $60 \mathrm{~min}$ away is weighted at $10 \%$ of an opportunity in the local municipality. This corresponds to actual travel behavior in the metropolitan region of Munich, as maximum travel time budgets are about one hour. The gravity-based accessibility $\mathrm{A}_{\mathrm{i}}$ to population and jobs is calculated in Excel for each municipality using Eq. (2). Then, the results are imported into GIS to visualize the relative accessibility by private and public transport and identify where spatial disparities exist. The result of the relative accessibility to population is shown in Fig. 1. Green areas illustrate where public transport accessibility is highly competitive with private transport accessibility, and red areas illustrate where it is not very competitive. For example, the relative accessibility by public transport in Munich is significantly better than in Ingolstadt due to the more extensive public transport network in Munich. Such results can be used to identify focus areas for improving public transport to reduce the disparities in accessibility. Although the TUM Accessibility Atlas had been created on the regional level of EMM, it was further developed on the county level for other projects. 


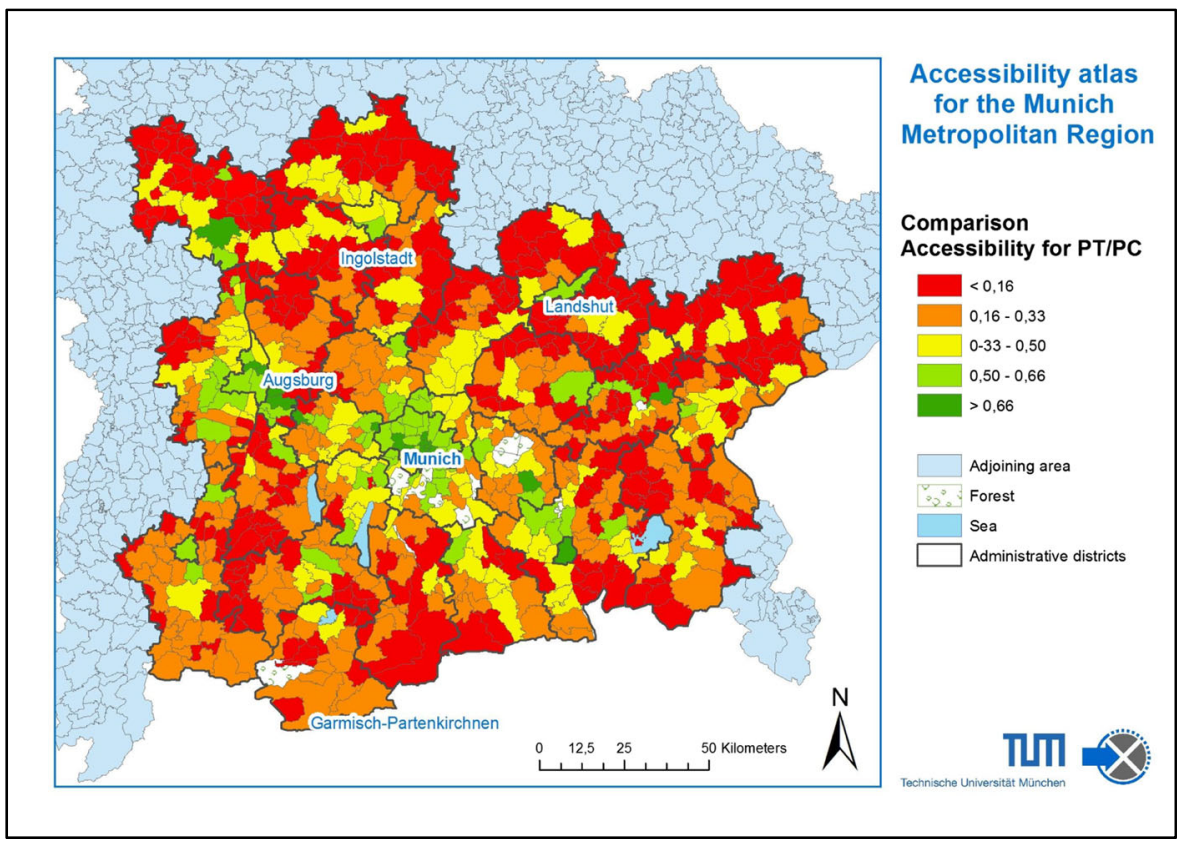

Fig. 1 Ratio of accessibility by public transport (PT) to private car (PC) in the EMM region

\subsection{Balancing Land-Use and Public Transport Accessibility for Sustainable Development}

Representing the interface between land-use and transport, accessibility is a suitable concept to foster integrated development on different spatial scales (see section 2.3). In contrast to the regional scale studied in section 3.2, the project "Climate Protection Concepts for the County of Fürstenfeldbruck" analyzed accessibility by public transport within the county, taking into account walking and cycling to the public transport stops. The aim of this project was to support better integration of land-use and transport by identifying locations with high accessibility and locations with high activity density. Areas where there are disparities between accessibility and activity density reflect a need for either higher density or better accessibility to improve sustainability.

\subsubsection{Modeling Accessibility to the Public Transport}

In this project, the public transport accessibility is considered as a combination of service quality of the public transport and the ease of access to public transport from a specific location: The accessibility of a location therefore increases with when more public transport stops and better service quality can be reached from a location.

First, the service quality of each public transport stop is defined using the public transport data, including three components based on the timetable during the morning peak from 6.00 to $9.00 \mathrm{am}$ :

- the travel time from each stop to all other stops, 
- the number of transfers from each stop to all other stops,

- the service frequency from each stop to all other stops.

Results are aggregated as one service quality indicator for each stop (Keller and Ji 2012). Second, the public transport stops are weighted based on their type (e.g. suburban train stops are weighted higher than bus stops). Third, three catchment areas based on the actual walking and cycling network are generated around the stops and are weighted based on their distance to the stops. The list of stops that are accessible, and the distance to them, is also identified. Finally, the accessibility of a specific location (overlapping area) is determined by the sum of the weighted service quality indicators of all reachable stops from that location. The process is specified with the formula and parameters below:

$$
A_{i}=\sum_{k=1}^{n} c_{k} \times t_{k} \times v_{k}
$$

- $\mathrm{n}$ : number of public transport stops that are reachable within a certain distance $(2 \mathrm{~km})$ from the evaluated location;

- $\quad \mathrm{c}$ : weighting of the distance of the reachable stops to the current location;

- $\mathrm{t}$ : weighting based on the type of the reachable stops (S-Bahn or non-SBahn);

- $\quad \mathrm{v}$ : quality of the reachable stops (aggregated service quality indicator, explained above).

Using this method, the accessibility to public transport actually represents the service quality of the public transport at a certain location. A sample result for the county of Fürstenfeldbruck is shown in Fig. 2.

\subsubsection{Disaggregating Population Data}

The population data is only available at the municipality and transport zone levels, which is insufficient for this project. Therefore, it must be disaggregated using the land use data, which has five categories:

- $\quad$ residential plots (Wohnbauflächen (W))

- mixed use plots (gemischte Bauflächen (M))

- residential area (allgemeine Wohngebiete (WA))

- mixed use area (Mischgebiete (MI))

- rural area (Dorfgebiete (MD))

A weight value indicating population density is assigned to each category: $\mathrm{W}=3$, $\mathrm{WA}=3, \mathrm{MI}=2, \mathrm{M}=2, \mathrm{MD}=1$. Within each municipality (or transport zone), the weighted summed area of all land use categories is calculated. The ratios between the size of each land use category over the weighted sum area are then calculated for each 


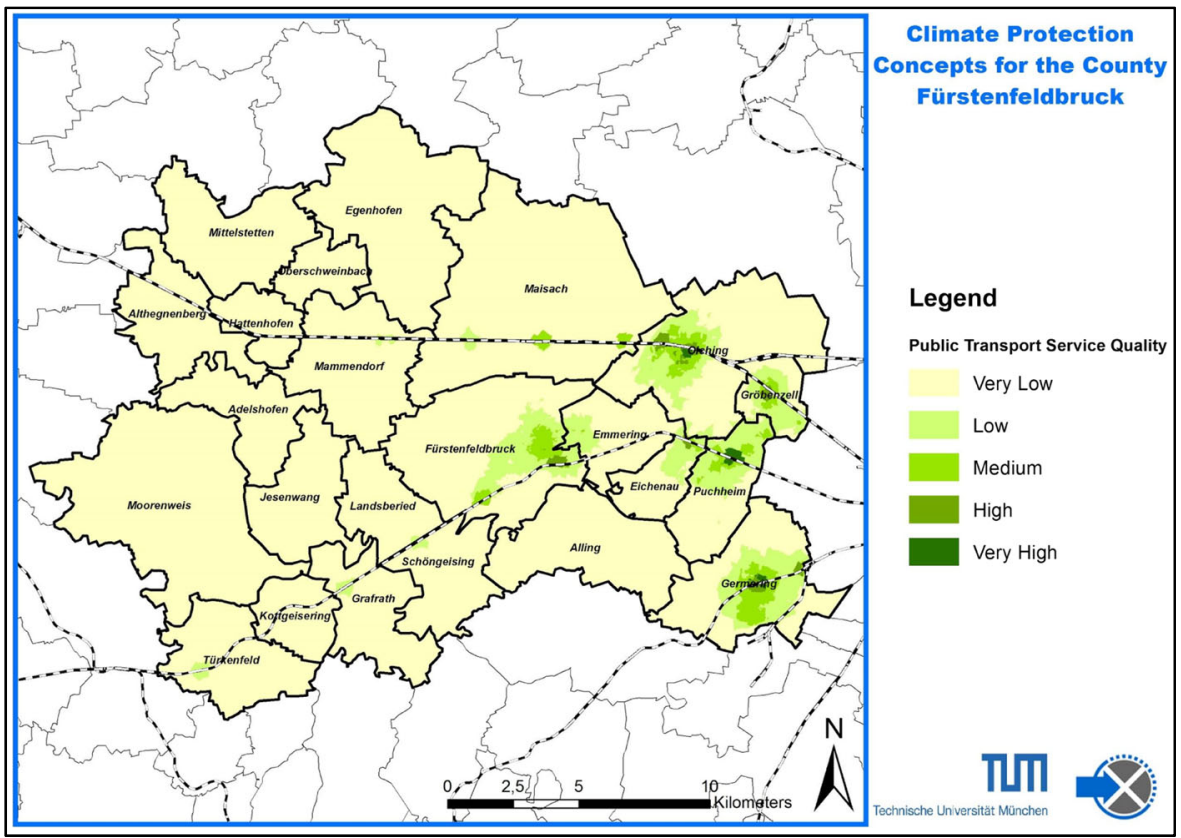

Fig. 2 Accessibility to public transport defined by service quality in the county of Fürstenfeldbruck

municipality. The population living within each land use category is obtained by multiplying this ratio by the total population of the municipality. Results of this analysis for the county of Fürstenfeldbruck are shown in Fig. 3.

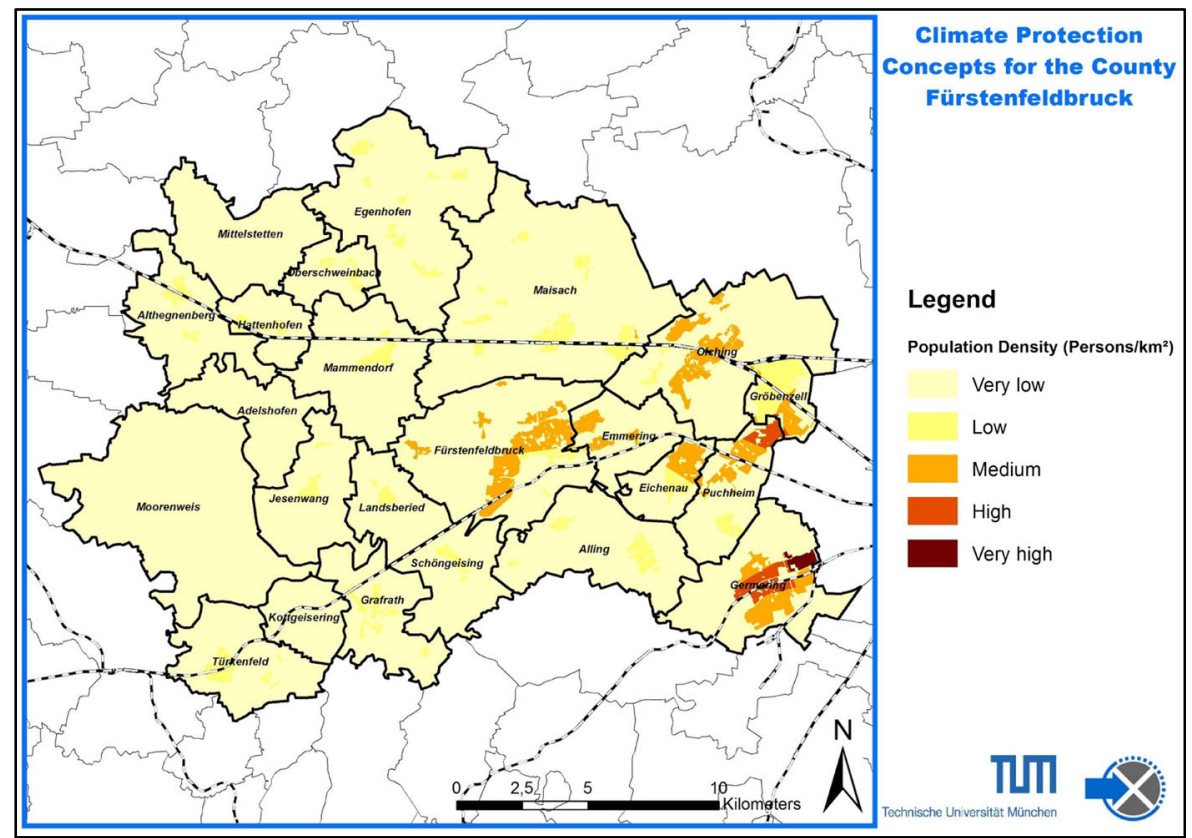

Fig. 3 Population density in the county of Fürstenfeldbruck 


\subsubsection{LUPTAI}

The land-use and public transport accessibility index (LUPTAI, see section 2.3) was implemented to achieve a better match between land-use density and public transport quality within the county of Fürstenfeldbruck. To calculate the location-specific indicators of population density and public transport accessibility, a raster dataset with a cell size of $20 \mathrm{~m} \times 20 \mathrm{~m}$ was created for the whole county of Fürstenfeldbruck. This means that one population density indicator and one public transport accessibility indicator has been calculated for every raster cell. Both indicators are then classified into 5 bins based on an 'Equal interval' class division. According to the LUPTAI methodology, the 25 density-accessibility pairs resulting from a crosswise combination of these indicators are classified as "accessibility surplus", "population surplus" or an intermediate balanced type, as shown in Fig. 4. The LUPTAI results are then mapped in Fig. 5, showing where disparities exist between the population density and the quality of public transport.

The result of the LUPTAI analysis assists planners and decision makers in choosing where to invest in public transport improvement (ideally there is population surplus, represented as red/brown areas in Fig. 5) and where to densify (where there is accessibility surplus, as blue areas in Fig. 5). However, there are certainly other considerations besides the LUPTAI result when making these decisions, such as environmental impacts.

\subsection{Vulnerability Assessments as a Means to Plan better Prepared Communities}

The TUM Accessibility Atlas was also used to better understand how rising mobility costs might affect the future of the EMM region. This was done through a vulnerability assessment which identified areas that will be most affected if mobility costs increase dramatically. In previous applications, the TUM Accessibility Atlas used travel time (for both public and private transport) as the impedance, as in classical transport planning. However, the TUM Accessibility Atlas is also capable of adopting other indicators such as energy consumption or travel cost as travel impedance, as long as there is relevant data available.

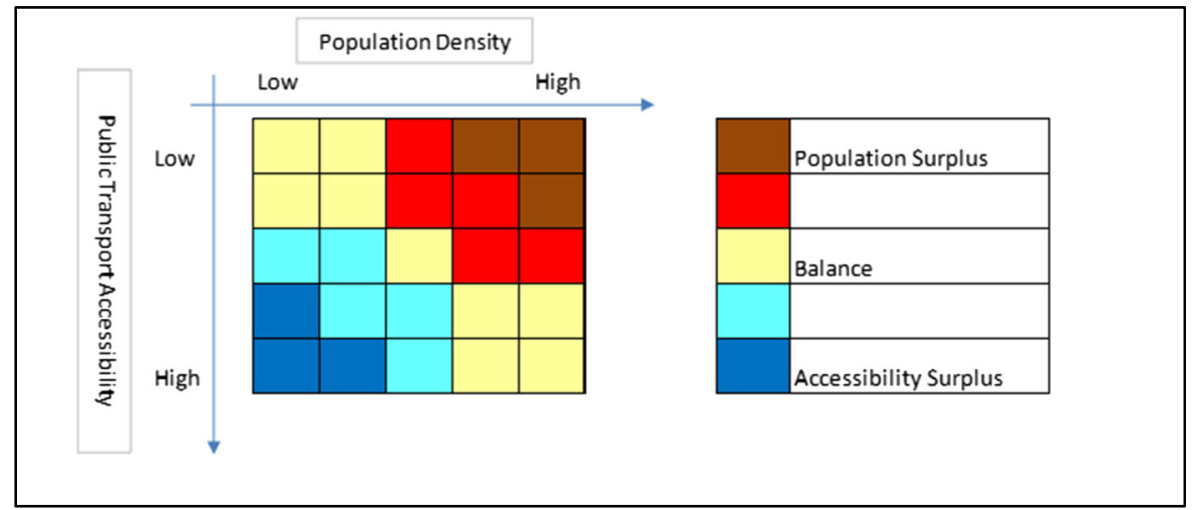

Fig. 4 LUPTAI legend 


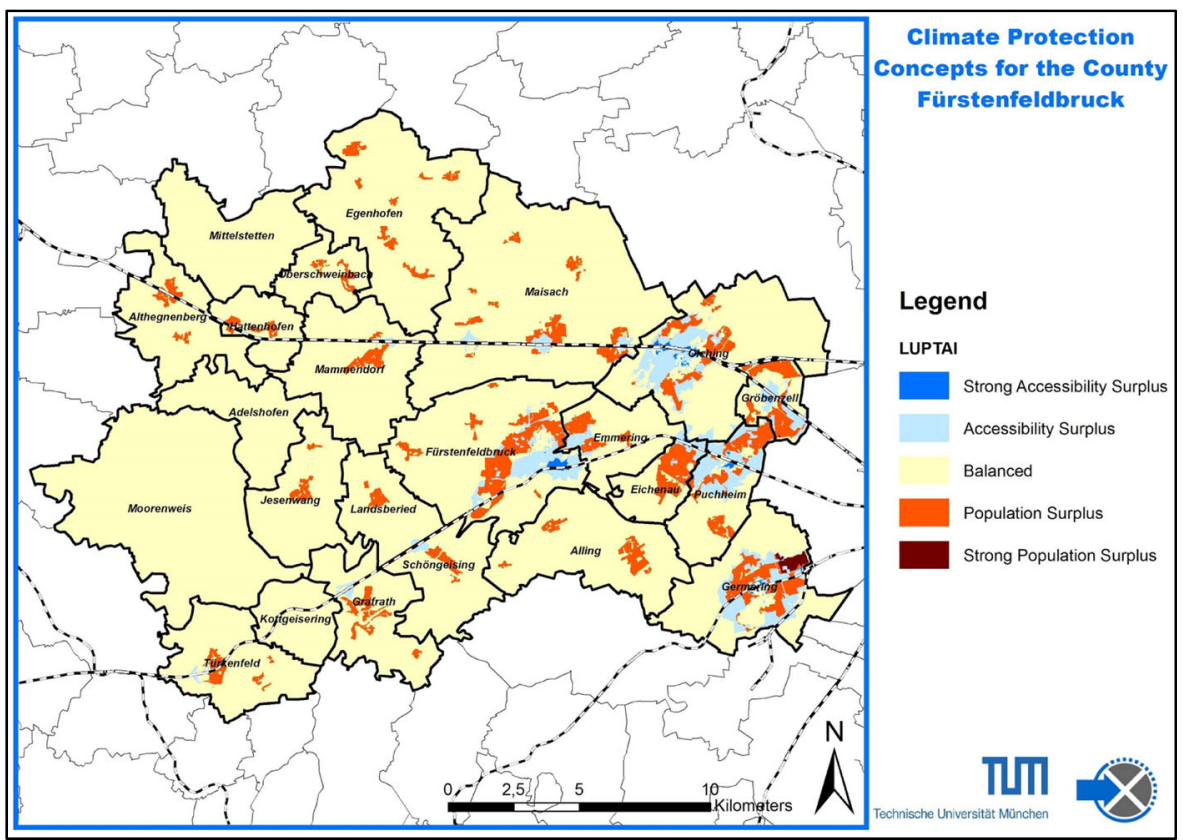

Fig. 5 LUPTAI analysis for the county of Fürstenfeldbruck

To compare the effect of increased mobility costs on households for both private and public transport, travel cost in terms of fuel price and public transport fare was integrated into the TUM Accessibility Atlas. For this study, a two-part assessment was performed for the municipalities in the EMM region. First, vulnerability was assessed on a regional scale to determine which municipalities are most vulnerable. Second, the vulnerability of selected municipalities was analyzed in detail by determining the impact of rising mobility costs on accessibility.

\subsubsection{Assessment of Vulnerability on a Regional Level}

The regional vulnerability assessment was performed using an index composed of three key indicators identified according to Kasperson et al. (2006) in section 2.4: exposure, sensitivity and resilience.

Exposure was defined as the vehicle-kilometers travelled per capita, which was the result of dividing total vehicle-kilometers from the transport data by the population data from GENESIS-online. Results were visualized in GIS environment. Sensitivity and resilience were calculated using the same approach. Sensitivity was measured using average monthly income and resilience was measured by accessibility to jobs. In this analysis, sensitivity represented socioeconomic disparities and resilience represented spatial disparities, while exposure and the overall vulnerability result represented both disparities. 
The vulnerability index is therefore a composite measure. However, the values for the exposure, sensitivity and resilience had very different magnitudes and ranges. Therefore, in order to make the three indicators quantitatively comparable, each indicator was converted to a linear scale from 1 to 100 . The following assumptions were adopted when scaling the values: the more one drives (highly exposed), the more vulnerable they are; the less one earns (highly sensitive), the more vulnerable; the better public transport accessibility one has (highly resilient), the less vulnerable. Going from the "worst" to "best" value of the three indicators, the scaled values were assigned from 1 to 100 where a higher number implies higher vulnerability. Finally, the vulnerability index was defined as the sum of the scaled values of the three indices (Büttner et al. 2013). The disparities measured by this vulnerability index are visualized in Fig. 6. The center of the EMM region was generally shown to be less vulnerable than the outskirts. However, a more detailed assessment of vulnerability was needed to better understand these results.

\subsubsection{Detailed Vulnerability Assessment Using Mobility Costs}

The second step in this study focused on how decision makers can respond to scenarios of increasing mobility costs in the Munich region, by exploring the regional vulnerability assessment results in more detail. Three municipalities were sampled as case studies to represent different settlement structures: the city of Fürstenfeldbruck, the suburb of Haar and the rural village of Kirchdorf an der Amper (Büttner and Wulfhorst 2014).

The TUM Accessibility Atlas was applied and further developed with cost models for both private and public transport in ArcGIS. The cost model for

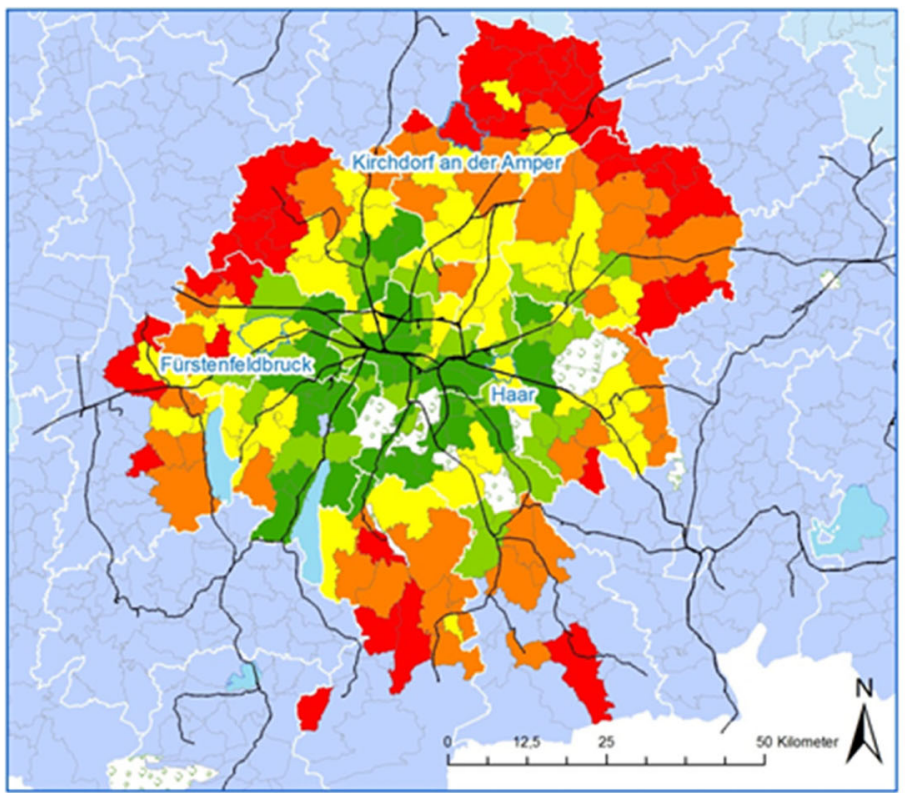

Fig. 6 Analysis of vulnerability to mobility cost increases for the EMM region
Stress tests for a sustainable mobility

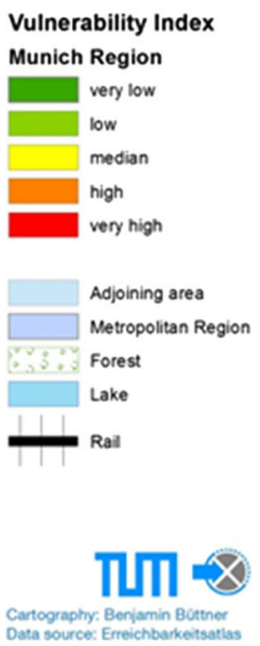


public transport was only developed for the three municipalities chosen as case studies.

Ten categories were created out of all points of interest (see Table 1 in Appendix) using different land-use sources above, including:

- Education

- Infrastructure

- Cultural and leisure facilities

- Service and sales

- Authorities and securities

- Retail

- Medical care

- Mixed use

- Social facilities

- Daily needs

\subsubsection{Calculating Fuel Consumption for the Private Transport}

The Handbook Emission Factors for Road Transport (HBEFA) provides emission factors for all current vehicle categories (passenger cars, light duty vehicles, heavy goods vehicles, urban buses, coaches and motor cycles), each divided into further categories, for a wide variety of traffic situations. Emission factors are provided for all regulated pollutants and the most important non-regulated pollutants, along with fuel consumption and $\mathrm{CO} 2$ emissions. Using these values from the HBEFA, fuel consumption results are calculated with the following settings:

- Country: Germany

- Vehicle category: passenger cars

- Components (pollutants): fuel consumption (gasoline and diesel)

- Years: 2013 to 2030 (yearly based)

- Fleet composition: emission factor weighted with fleet composition by" 'BAU' (D)" (Business As Usual) where the following traffic situations are defined:

- Rural area (labeled as "Land" in output) + LOS "Freeflow"

- Urban area (labeled as "Agglomeration" in output) + LOS "Stop + go"

- Aggregation level of output: "per vehicle-category and technology/fuel type"

The results for average fuel consumption of both gasoline and diesel vehicles are returned, measured in liters/vehicle-km, for every road category under various speed limits in each urban area. For example, with the 2013 fleet composition in Germany, an average of $45.54 \mathrm{~g}$ of gasoline are consumed to travel one vehicle-kilometer on a rural motorway with a speed limit of $80 \mathrm{~km} / \mathrm{h}$. The amount of fuel consumption in grams can then be converted into liters using the gasoline density of $750 \mathrm{~g} / 1$ and the diesel density of $830 \mathrm{~g} / \mathrm{l}$. 


\subsubsection{Modeling Isocost Opportunities for Private Transport}

As mentioned in section 3.3, the street network from OSM first had to be cleaned by eliminating the street links that are not for vehicles. Second, the cleaned street network was further categorized into "within urban area" and "outside of urban area" by using the CLC data. Third, as the naming convention for road types in OSM and in HBEFA is not identical, these had to be matched. ${ }^{2}$

Each street link in OSM which has a specific road type, a speed limit and a location type (within or outside of urban area) can be matched to the corresponding HBEFA fuel consumption category. The length of each street link is calculated in kilometers in ArcGIS and multiplied by the HBEFA fuel consumption data in grams $/ \mathrm{km}$. This yields how many liters of gasoline and diesel fuel are consumed on each street link in OSM, which is then stored in a newly created attribute of the OSM road network shapefile. Using this attribute as "Cost", a Network Dataset of the road network is set up in ArcGIS, enabling the calculation of contours ("Service Areas" in Network Analyst of ArcGIS) for the fuel consumption (instead of time or distance) of passenger cars.

For this study, three scenarios for gasoline price increases were analyzed: $1.55 € / \mathrm{L}$ (the average price at the time of the project in 2013), 2.11€/L (representing a crude oil cost of $\$ 200 /$ barrel converted using the currency exchange rate at the time), and 4.65 $€ / \mathrm{L}$ (representing a threefold fuel price increase). A budget of $2.50 €$ was assigned to see how far one can travel by passenger car. For the three scenarios of fuel price increases, $2.50 €$ is equivalent to $1.6131,1.1851$ and 0.5381 of fuel consumption respectively. The accessible area is then calculated for each level of fuel consumption. To simplify the comparison of the accessible areas by private and public transport, the municipality's main public transport stop is used as the origin for each municipality (the suburban train stop in Fürstenfeldbruck, the suburban train stop in Haar and the bus stop at the center of Kirchdorf an der Amper).

\subsubsection{Modeling Isocost Opportunities for Public Transport}

The tariff structure of the public transport in the Munich region is relatively complex. From one stop to another, the ticket price may vary depending on where the starting and ending stops are located, when the trip is made, the type of ticket purchased (one-way, day, week, month, or year), whether the traveler is alone or in a group, etc. Hence, setting up a full cost model for the public transport, taking into account all the possible tariffs, would be an extremely large effort.

For this reason, the cost model of public transport was greatly simplified by considering only the one-way ticket as a tariff option. Also, only trips starting from the main public transport stop in each target area were modelled. To find out which stops were accessible from the three main stops with a one-way ticket of $2.50 €$, the start and end stops were manually entered on the website of the local public transport authority MVV to determine all travel possibilities. The possible end stops were stored in a Microsoft Excel file, which was then linked to the shapefile for the public transport stops by using the "join" function in ArcGIS. Finally, the public transport isochrones

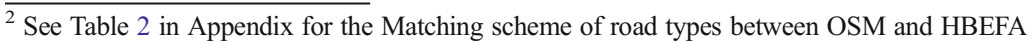


for a cost of $2.50 €$ were approximated by manually linking the end stops that are located farthest from the origin.

Thus the comparison between public and private transport with a given budget of $2.50 €$ can be visualized by mapping isocost contours for the three target areas. The result of this analysis for the target area of Haar is shown in Fig. 7. The lack of affordable accessibility to certain areas demonstrates the spatial disparities, while the more affordable accessibility by private car is disadvantageous to socioeconomic groups that cannot afford their own vehicle. Policies and measures that expand the area that can be reached with a given public transport can help resolve both of these issues.

\subsubsection{Modeling Neighbourhood Accessibility}

In addition to considering the motorized transport modes, walking is also modelled to show the neighbourhood mobilities for the three target areas. Here, OSM data was used to create the pedestrian network, since there is no official dataset available. Nevertheless, the OSM road network can provide very detailed information about aspects that are of great importance to pedestrians, including stairs, footpaths and tracks which are not official streets, etc. Despite the many quality issues with OSM data at the time of the project, there was no better data source available for modeling the pedestrian network.

Similar to the setup of the motorized network, street links that are not open to pedestrians are removed from the original dataset, which for instance include all the links of type "motorway". Due to limited resources, a fully edited pedestrian network for the three target areas was not possible, let alone for the whole study area. Therefore,

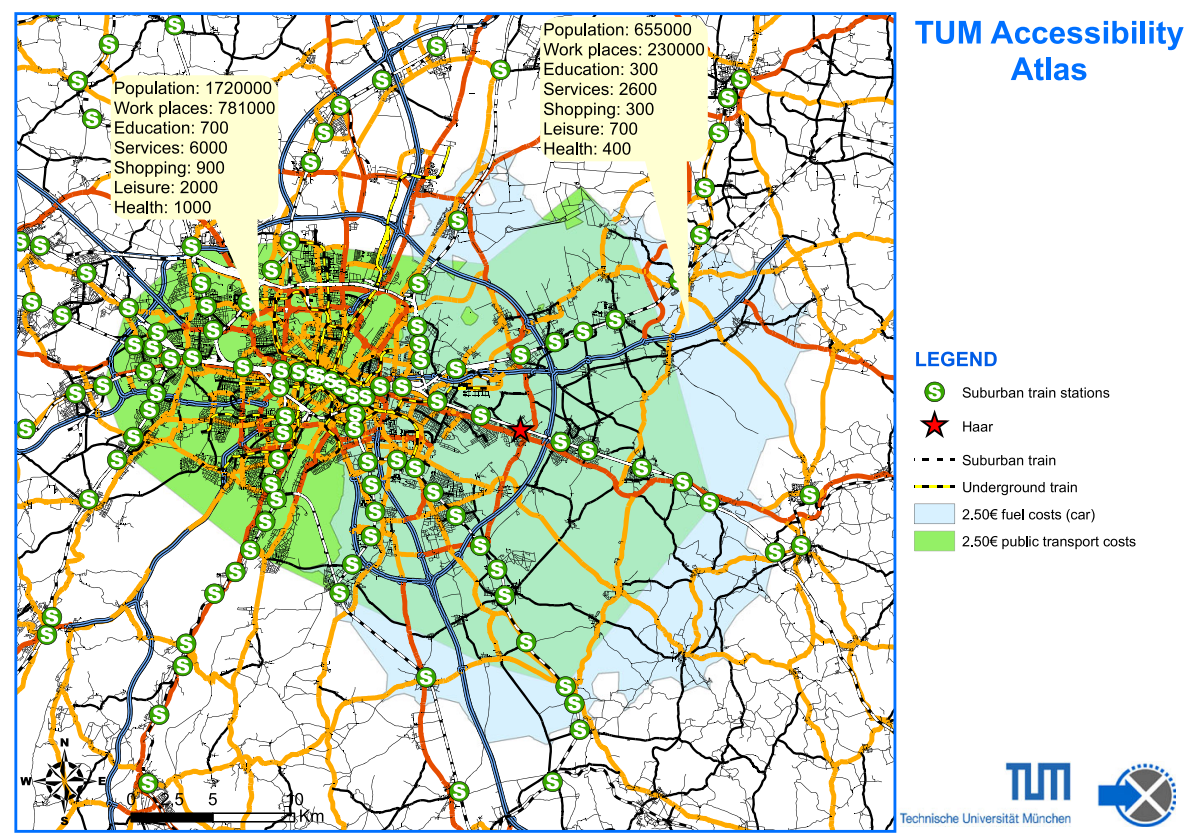

Fig. 7 Isocost opportunities by private vs public transport for the target area of Haar 


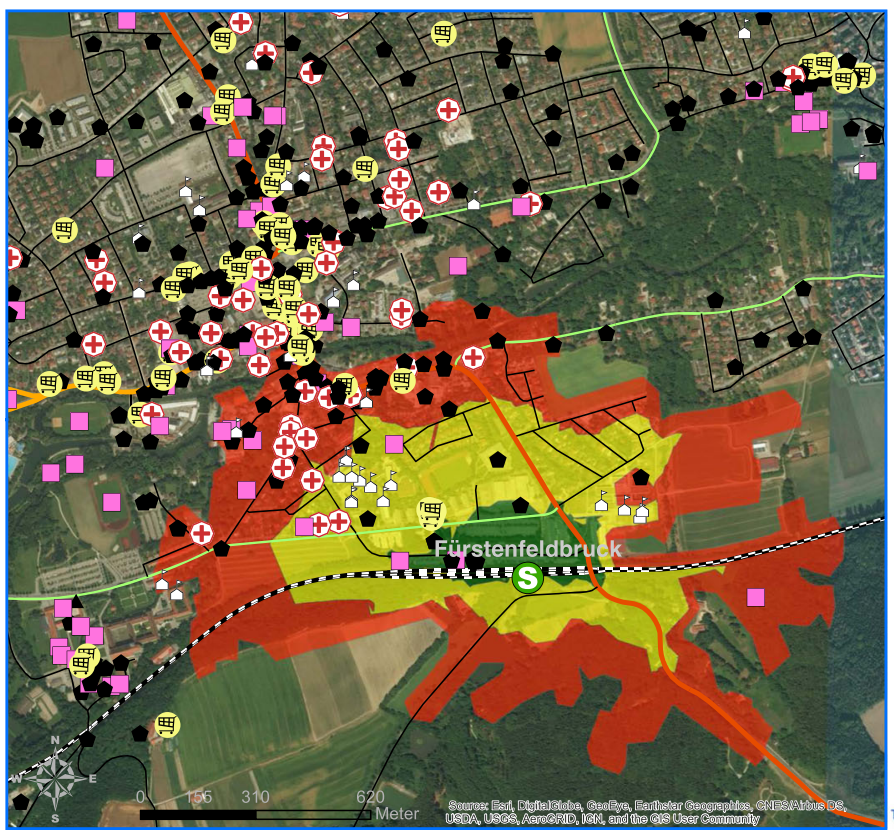

TUM Accessibility

Atlas

LEGEND

S Suburban train station

5 Education

- Services

曹 Shopping

$\square$ Leisure

$(\oplus$ Health

Catchment area by foot

5 Min.

10 Min.

15 Min.

Fig. 8 Neighborhood accessibility analysis for a suburban train station in the city of Fürstenfeldbruck

it is assumed that all the other links are allowed for pedestrians. A Network Dataset is set up based on the OSM road network shapefile without motorways, in which the length of the streets is used as the "cost" attribute.

With an assumed walking speed of $4 \mathrm{~km} / \mathrm{h}$, isochrones are created for distances of $333 \mathrm{~m}, 666 \mathrm{~m}$ and $1000 \mathrm{~m}$ (corresponding to $5 \mathrm{~min}, 10 \mathrm{~min}$ and $15 \mathrm{~min}$ of time budget) using the Network Analyst. Figure 8 shows an example of this analysis for the suburban train station serving the city of Fürstenfeldbruck. Increasing the amount of points of interest that can be reached on foot is another way to reduce vulnerability to rising mobility costs.

To resolve the limitations in the tool's walking accessibility analysis, a complete and fully edited pedestrian network is now being constructed as part of another project.

More information about all the projects in this chapter can be found on their websites. ${ }^{3}$ Since these projects were completed, the TUM Accessibility Atlas has been updated and further developed continuously on various scales, from the regional to the local level. New data has also been integrated into the Atlas while old data has been brought up to date. Future improvements of the TUM Accessibility Atlas are discussed in the following chapter.

\section{Future Developments}

Previous applications have proven that the TUM Accessibility Atlas is a valuable instrument to enrich planning processes and support political decision-making

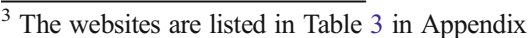


(Büttner and Wulfhorst 2016). Nevertheless, there is potential for further improvements and extensions of the tool. The development path is two-fold: On the one hand, there is a need to further enhance the instrument's usability for planning processes by making it more flexible and dynamic. On the other hand, there are several options to broaden its thematic scope in order to tackle a wider variety of land-use and transport related problems.

\subsection{Improving Usability}

One of the most pressing needs is for accessibility maps to become more flexible and dynamic to improve usability. This makes these tools more powerful, enables better communication, and brings ordinary citizens into the fold to harness the power of crowdsourcing. A broad case study of the usability of accessibility instruments in 16 countries found that the ability to visualize different scenarios in real time was the mostdemanded feature by planners and practitioners (te Brömmelstroet et al. 2014). This feature is also important to ordinary citizens as well as to practitioners creating future scenarios and assessing land-use and transport measures. In a study of how visualization impacts communication with citizens, (Warren-Kretzschmar and Tiedtke 2005) found that participants wished they could visualize their ideas and suggestions immediately and that real-time capabilities "would be an asset in the communication with citizens during the planning process", making them more active as participants in planning.

The idea of turning citizens into active participants is best reflected in the rise of crowdsourcing, especially when tools are powerful and dynamic enough that anyone can test their ideas in real-time over the internet. This carries great potential but also new challenges. In 2009, a pilot project was launched to crowdsource designs for a bus stop and received many excellent submissions. The study creators caution that building and maintaining a vibrant online community to submit ideas is not easy, and that too many high-quality submissions can discourage amateur participation. However, they also express optimism that with proper care, such methods could be extended to other problems in transport planning, such as the planning of bus routes (Brabham et al. 2010). By improving tools like the TUM Accessibility Atlas to be interactive, dynamic, and web-based there is great potential to improve communication among planners and with citizens, and gather valuable crowd-sourced input.

\subsection{Expanding the Scope of Analysis}

In addition to usability improvements regarding the tool's analytical capabilities, enhancing the scope of analysis will be another focus of future development. The usability of accessibility instruments for planning practice not only depends on their performance and implementation, but also on the nature and diversity of planning issues that can be addressed (Papa et al. 2016). Cumulative opportunity measures have been applied previously using travel time and monetary travel costs as spatial impedance. Within the Interreg Alpine Space project "Alpine Smart Transport and Urbanism Strategies", $\mathrm{CO}_{2}$ emissions will be implemented as a travel cost indicator, helping to analyze the number of opportunities available within individual emission budgets. Emissions factors will be assigned to the networks of both public and private transport. 
The analysis will provide input for strategic discussions on more sustainable landuse and transport planning in both semi-urban and rural areas. These will be within the context of current debates on emission reduction goals. This emission-based accessibility approach can be applied not only from the perspective of individual households, but also to evaluate activity locations based on their $\mathrm{CO}_{2}$ footprint. Accessibility analyses comparing different transport modes enable an estimation of mode share and thus transport-related emissions. Existing points of interest, as well as locations under consideration for future development, can be evaluated based on the emissions they generate. Such analysis can help to identify suitable locations for further densification based on their accessibility potential. More intensive land-use in central areas will cause different effects compared to new developments in peripheral locations.

Accessibility models similar to Bertolini's node-place model (1999) or the LUPTAI (Pitot et al. 2006), which highlight imbalances between accessibility potential and existing land-use, will also cause a shift towards more actively supporting politicians and planners in their decision-making. Therefore, a specific application planned for the TUM Accessibility Atlas aims to enhance urban structure with respect to the distribution of employment and housing. Accessibility to the working population on a detailed spatial scale will be compared to the present employment intensity. This application highlights the potential for more sustainable future development of workplaces, options for improving the transport structure, and the need to provide additional housing in a growing metropolitan region.

Regarding the four dimensions of accessibility (see section 2.1), there is growing interest in the temporal component of accessibility. The use of new data sources enables time-sensitive accessibility analysis in ArcGIS (for recent application see Moya-Gómez et al. 2017). This trend will be followed with a test implementation of General Transit Feed Specification (GTFS) data in combination with an OSM pedestrian network for the TUM Accessibility Atlas in the near future, allowing for a detailed accessibility analysis at different times of day.

On the neighborhood level, the TUM Accessibility Atlas allows the analyses of routing and distance isochrones based on the walking network, as mentioned in section 3.4. One of the further developments planned for the tool is the integration of quantitative walkability indices into the model. Specifically, there is still a need to research how to quantitatively represent the objective walking environment perceived by subjective pedestrians.

\section{Conclusions}

Munich's exceptionally strong labor market and its appeal as a tourist destination has caused the city to consistently rise in popularity. The growth in resident population and annual tourist visits has posed several challenges for the city, including rising living costs, farther commuting distances, and a strained transport network. Realizing that a solution to these problems requires regional collaboration, the Metropolitan Region of Munich (EMM) was formed in 2007 to enable closer cooperation, better dialogue, and a jointly developed vision of the future for its constituent counties, cities, and various partner institutions. In support of integrated land-use 
and transport planning at a regional level, there was a clear need for an instrument to analyze the issues posed by increases in population, living costs, and commuting distances.

The Technical University of Munich (TUM) established the TUM Accessibility Atlas in 2009 as a strategic instrument for analysis and planning across all transport modes and on various spatial scales for the metropolitan region. It has been supported by motivated stakeholders, who emphasized the need to address these issues and develop a shared regional identity. Accessibility was chosen as the most effective way to measure these impacts and achieve these improvements because of repeated success in bridging the gap between theory and practice. Various applications of this tool have demonstrated the power of maps in policy- and decision making to visualize disparities in accessibility, both spatially and by transport mode. For example, the tool has been quite effective answering the three main questions of this research: how to reduce car dependency in the region to improve its environmental and social sustainability, how to achieve better integration of land-use and transport by identifying locations where there is a mismatch between the levels of accessibility and activity density, and how to reduce the region's vulnerability to shocks in gasoline prices by highlighting the most vulnerable areas that should be improved. Lessons from using the TUM Accessibility Atlas have also shown such tools rely on several characteristics to be successful, namely:

- High quality, up-to-date data from various sources: to ensure that output accurately represents the current situation

- Active participation and support from stakeholders: to create consensus-driven, clearly-articulated policy goals that steer regional governance

- Clear and transparent indicators: to create a shared language in which stakeholders with different backgrounds can effectively collaborate

The usability of the TUM Accessibility Atlas benefits from its design as a relatively simple instrument, and its ability to show initial results at an early stage. From here, the tool can be incrementally improved based on the specific planning policy goals and the initial feedback from stakeholders.

Future development of the TUM Accessibility Atlas will target goals that help it become an even more effective visualization and planning support tool. Regarding usability, the tool will become more dynamic, interactive and also web-based. This will stakeholders to test potential scenarios and solutions in real-time, and also allow the public to access it and test their own ideas, enabling more active community participation and crowd-sourced solutions. Regarding features, the tool will be able to analyze how household travel decisions are made and how potential locations for activities and employment centers affect $\mathrm{CO} 2$ emissions. This will provide key support for environmentally sustainable land use and transport planning in the region.

Many other cities are also facing considerable population growth and similar resulting problems, so there is a great deal to be learned from the approach taken by the Munich region. The development of well-designed instruments to visualize accessibility and the associated spatial and socioeconomic disparities has proven to be especially effective in supporting and steering regional land-use and transport planning. 
Acknowledgements We would like to thank the anonymous reviewers as well as the editors of this special issue for their constructive and very helpful comments to significantly improve the paper.

\section{Appendix}

Table 1 Dataset overview of the TUM Accessibility Atlas for selected projects

\begin{tabular}{|c|c|c|c|}
\hline Data & Type & Information & $\begin{array}{l}\text { Application } \\
\text { project }\end{array}$ \\
\hline
\end{tabular}

HAFAS

MVV data

Passenger car travel time matrix

Passenger car travel time (exemplary)

Road network

Emission/Fuel consumption data for private transport

Geography data for all municipalities

Population data
Public transport

HAFAS data that includes the public transport

EMM stops, lines and timetables. HAFAS is a timetable information system from the company HaCon and is used by many transport agencies (e.g. the German Railway) for timetable information

Public transport Public transport stop locations, network, tariff data and timetable data provided by the Munich Transport and Tariff Association (MVV, Münchner Verkehrs- und Tarifverbund $\mathrm{GmbH}$ ) based on the regional transport model; The data is edited and analyzed with the PTV VISUM 10.0 transport modeling software to calculate travel time and service quality indicators which are then imported into the ArcGIS environment.

Private transport Provided by the Federal Institute for Research on Building, Urban Affairs and Spatial Development (BBSR) on the municipality level

Private transport Travel time data from the website map24.de by the company NAVTEQ is used to check the plausibility of the travel times from OpenStreetMap (OSM) data

Private transport OSM acquired from the company Geofabrik which provides data converted in shapefile format

FFB, Stress Test

EMM

EMM

EMM. FFB, Stress Test

Private transport Emission/Fuel consumption data for private transport: data from the "Handbook of Emission Factors for Road Transport" (HBEFA, version 3.1) is used for the calculation of fuel consumption

Structural data

The geo-referenced data for all municipalities are acquired from the ATKIS dataset provided by the Federal Agency for Cartography and Geodesy and the Bavarian State Office for Survey and Geoinformation to visualise the EMM region

Structural data Acquired from the GENESIS-Online database, aggregated at the municipality level, which is provided by the Federal Statistical Office for the public
EMM, FFB, Stress

Test 
Table 1 (continued)

\begin{tabular}{|c|c|c|c|}
\hline Data & Type & Information & $\begin{array}{l}\text { Application } \\
\text { project }\end{array}$ \\
\hline Employment & Structural data & GENESIS-Online & EMM \\
\hline Commuters & Structural data & GENESIS-Online & EMM \\
\hline Income & Structural data & GENESIS-Online & Stress Test \\
\hline Hotel bed count & $\begin{array}{l}\text { Point-of-Interest } \\
\text { (POI) }\end{array}$ & GENESIS-Online & EMM \\
\hline Research facilites & POI & $\begin{array}{l}\text { Provided by the Bayrisches Staatsministerium für } \\
\text { Wissenschaft, Forschung und Kunst }\end{array}$ & EMM \\
\hline Hospitals & POI & $\begin{array}{l}\text { Provided by the Bayerisches Staatsministerium } \\
\text { für Gesundheit und Pflege }\end{array}$ & EMM \\
\hline Ski resorts & POI & Provided by www.bergfex.de & EMM \\
\hline Public castles & POI & $\begin{array}{l}\text { Provided by the Bayerische Verwaltung der } \\
\text { staatlichen Schlösser, Gärten und Seen }\end{array}$ & EMM \\
\hline $\begin{array}{l}\text { Google and OSM data } \\
\text { on POI }\end{array}$ & POI & Acquired from Google and OSM & Stress Test \\
\hline Field survey of activities & POI & POI data from field survey & Stress Test \\
\hline $\begin{array}{l}\text { CORINE Land Cover } \\
\text { (CLC) data }\end{array}$ & Land-use data & $\begin{array}{l}\text { CLC data provided by the European } \\
\text { Environmental Agency (EEA) are used to } \\
\text { identify the urban areas and their density cen- } \\
\text { ters. For this project, the most up-to-date data } \\
\text { is from the year } 2006\end{array}$ & EMM \\
\hline MVV Land-use data & Land-use data & $\begin{array}{l}\text { Data on the functions of all buildings within the } \\
\text { MVV region are provided by the MVV in form } \\
\text { of a polygon shapefile. These polygons are } \\
\text { converted to point features through the X and } \\
\text { Y coordinates of their centroids }\end{array}$ & Stress Test \\
\hline
\end{tabular}

Table 2 Matching scheme of road types between OSM and HBEFA

\begin{tabular}{lll}
\hline OSM & HBEFA (Land) & HBEFA (Agglomeration) \\
\hline motorway__link) & Motorway-Nat. & Motorway-City \& Motorway-Nat. \\
primary__link) & TrunkRoad/Primary-Nat. & Trunkroad/Primary-City \\
secondary(_link) & Distributor/Secondary & Distributor/Secondary \\
tertiary(_link) & Local/Collector & Local/Collector \\
trunk__link) & TrunkRoad/Primary-Nat. & Trunkroad/Primary-City \\
living_street & Access-residential & Access-residential \\
residential & Access-residential & Access-residential \\
road & Access-residential & Access-residential \\
unclassified & Access-residential & Access-residential \\
\hline
\end{tabular}


Table 3 Websites for the mentioned projects

\begin{tabular}{ll}
\hline Project & Website \\
\hline $\begin{array}{l}\text { An Accessibility Atlas for the } \\
\text { European Metropolitan Region } \\
\text { of Munich (EMM) }\end{array}$ & https://www.metropolregion-muenchen.eu/ \\
$\begin{array}{l}\text { Climate Protection Concepts for the } \\
\text { County of Fürstenfeldbruck }\end{array}$ & http://www.lra-ffb.de/lra/bau/klimaschutz/klimaschutz-home.shtml \\
$\begin{array}{l}\text { Vulnerability assessments as a means } \\
\text { to plan better prepared communities }\end{array}$ & $\begin{array}{l}\text { http://www.moreco-project.eu/ } \\
\text { https:/www.sv.bgu.tum.de/de/forschung-und-beratung/projekte/projekte/ } \\
\text { stress-tests-for-a-sustainable-mobility/ }\end{array}$ \\
\end{tabular}

Open Access This article is distributed under the terms of the Creative Commons Attribution 4.0 International License (http://creativecommons.org/licenses/by/4.0/), which permits unrestricted use, distribution, and reproduction in any medium, provided you give appropriate credit to the original author(s) and the source, provide a link to the Creative Commons license, and indicate if changes were made.

\section{References}

AASHTO: American Association of State Highway and Transportation Officials (2013) Commuting In America 2013: The National Report on Commuting Patterns and Trends. Brief 10. Commuting Mode Choice, October 2013, Washington, DC

Benenson I, Martens K, Rofé Y, Kwartler A (2011) Public transport versus private car GIS-based estimation of accessibility applied to the Tel Aviv metropolitan area. Ann Reg Sci 47(3):499-515. https://doi. org/10.1007/s00168-010-0392-6

Bertolini L (1999) Spatial development patterns and public transport: the application of an analytical model in the Netherlands. Plan Pract Res 14(2):199-210. https://doi.org/10.1080/02697459915724

Bertolini L, le Clercq F, Kapoen L (2005) Sustainable accessibility: a conceptual framework to integrate transport and land use plan-making. Two test-applications in the Netherlands and a reflection on the way forward. Transp Policy 12(3):207-220. https://doi.org/10.1016/j.tranpol.2005.01.006

Bina M, Kockelman KM, Suescun D (2006) Location choice vis-à-vis transportation: the case of recent homebuyers. University of Texas, Austin

Brabham D, Sanchez T, Bartholemew K (2010) Crowdsourcing public participation in transit planning: preliminary results from the next stop design case. Conference Paper for the annual meeting of the Transportation Research Board of the National Academies, Washington, DC

Büttner B, Wulfhorst G (2016) The TUM Accessibility Atlas as a tool for fostering decision making processes on sustainable mobility in the metropolitan region of Munich. 14th WCTR 2016, Proceedings. Shanghai

Büttner B (2017) Consequences of sharp increases in mobility costs on accessibility. Suggestions for Individual and Public Development Strategies. Dissertation at Technical University of Munich (TUM), Chair for Urban Structure and Transport Planning, Munich

Büttner B, Keller J, Wulfhorst G (2010) Ein Erreichbarkeitsatlas für die Europäische Metropolregion München - Schlussbericht. Final Project Report, Technical Univeristy of Munich (TUM), Chair of Urban Structure and Transport Planning, Munich

Büttner B, Keller J, Wulfhorst G (2011) Erreichbarkeitsatlas - Grundlagen für die Zukunft der Mobilität in der Metropolregion München. Technical Univeristy of Munich (TUM), Chair of Urban Structure and Transport Planning, Munich

Büttner B, Wulfhorst G (2014) MORECO II: recommendations for decision-makers to respond to increasing mobility costs in the Munich region. Technical Univeristy of Munich (TUM), Chair of Urban Structure and Transport Planning, Munich

Büttner B., Wulfhorst G., \& Evans J. (2016). Ensuring accessibility to daily activities for different population segments with respect to sharp increases in mobility costs. In Geurs K, Patuelli R And Dentinho T (eds.), 
Accessibility, equity and efficiency. Challenges for transport and public services. Northampton: Edward Elgar

Büttner B, Wulfhorst G, Ji C, Crozet Y, Mercier A, Ovtracht A (2013) The impact of sharp increases in mobility costs analysed by means of the vulnerability assessment. Conference Paper, WCTR, At Rio de Janeiro

Büttner B, Zhao J, Thierstein A, Wulfhorst G, Förster A, Sterzer L (2014) When growth stresses development. Interdependencies between housing, employment and mobility in the Munich metropolitan region. RSAI 10th world congress, proceedings, Bangkok

Calthorpe P (1993) The next American metropolis the next American metropolis: ecology, community and the American dream (pp. 15-38). Princeton Architectural Press, Princeton

Caschili S, Reggiani A, Medda F (2015) Resilience and vulnerability of spatial economic networks. Netw Spat Econ 15(2):205-210. https://doi.org/10.1007/s11067-015-9283-9

Cats O, Jenelius E (2014) Dynamic vulnerability analysis of public transport networks: mitigation effects of real-time information. Netw Spat Econ 14(3-4):435-463. https://doi.org/10.1007/s11067-014-9237-7

Cervero R (1998) The transit metropolis: a global inquiry. Island Press, Washington, DC

Cervero R, Ferrell C, Murphy S (2002) Transit-oriented development and joint development in the United States: a literature review. Research Results Digest (52). Transportation Research Board, Transit Cooperative Research Program, Washington, DC

Chen A, Yang C, Kongsomsaksakul S, Lee M (2007) Network-based accessibility measures for vulnerability analysis of degradable transportation networks. Netw Spat Econ 7(3):241-256. https://doi. org/10.1007/s11067-006-9012-5

Cheng J, Bertolini L (2013) Measuring urban job accessibility with distance decay, competition and diversity. J Transp Geogr 30:100-109. https://doi.org/10.1016/j.jtrangeo.2013.03.005

Chorus P, Bertolini L (2011) An application of the node place model to explore the spatial development dynamics of station areas in Tokyo. J Transp Land Use 4(1):45-58

Cortright J (2009) Walking the walk: how walkability raises home values in U.S. cities. CEOs for Cities. Impresa Inc., Washington, DC

Dalvi MQ, Martin KM (1976) The measurement of accessibility: some preliminary results. Transportation 5(1):17-42. https://doi.org/10.1007/BF00165245

de Graaff T, Debrezion Andom G, Rietveld P (2012) The impact of accessibility on house prices: an application to large urban planning and infrastructure projects in the Netherlands. In: Geurs KT, Krizek KJ, Reggiani A (eds) Accessibility Analysis and Transport Planning. Challenges for Europe and North America (NECTAR series on transportation and communications networks research). Edward Elgar, Northampton, pp 154-173

Di Paolo A, Matas A, Raymond JL (2017) Job accessibility and job-education mismatch in the metropolitan area of Barcelona. Pap Reg Sci 96(S1):S91-S112

Dong X, Ben-Akiva ME, Bowman JL, Walker JL (2006) Moving from trip-based to activity-based measures of accessibility. Transp Res A Policy Pract 40(2):163-180. https://doi.org/10.1016/j.tra.2005.05.002

EMM eV (2016) Daten und Fakten. Retrieved from Metropolregion München: https://www.metropolregionmuenchen.eu/metropolregion-muenchen/daten-und-fakten

Fotheringham AS, O'Kelly ME (1989) Spatial interaction models: formulations and applications. Kluwer Academic, Dordrecht

Geurs K, Ritsema van Eck JR (2001) Accessibility measures: review and applications. RIVM, Bilthoven

Geurs K, van Wee B (2004) Accessibility evaluation of land-use and transport strategies: review and research directions. J Transp Geogr 12(2):127-140. https://doi.org/10.1016/j.jtrangeo.2003.10.005

Handy SL, Niemeier DA (1997) Measuring accessibility: an exploration of issues and alternatives. Environ Plan A 29(7):1175-1194. https://doi.org/10.1068/a291175

Hansen W (1959) How accessibility shapes land use. J Am Inst Plann 25(2):73-76. https://doi.org/10.1080 /01944365908978307

Hess DB (2005) Access to employment for adults in poverty in the buffalo-Niagara region. Urban Stud 42(7): 1177-1200. https://doi.org/10.1080/00420980500121384

Hu L (2014) Changing effects of job accessibility on employment and commute: a case study of Los Angeles. Prof Geogr 67(2):154-165

Huber P (2014) Are commuters in the EU better educated than non-commuters but worse than migrants? Urban Stud 51(3):509-525. https://doi.org/10.1177/0042098013498282

Kasperson JX, Kasperson RE, Turner BL, Hsieh W, Schiller A (2006) Vulnerability to global environmental change. In: Diekman A, Dietz T, Jaeger CC, Rosa EA (eds) The human dimensions of global environmental change. MIT Press, Cambridge

Keller J, Ji C (2012) Developing accessibility models to foster climate-efficient regional development. In: NECTARRSAI special session on modelling accessibility in spatial-economic Networks, May 9-12, 2012, Timisoara 
Koenig JG (1980) Indicators of urban accessibility: theory and application. Transportation 9(2):145-172. https://doi.org/10.1007/BF00167128

Manaugh K, El-Geneidy A (2012) Who benefits from new transportation infrastructure? Using accessibility measures to evaluate social equity in public transport provision. In: Geurs K, Krizek K, Reggiani A (eds) Accessibility and transport planning: challenges for Europe and North America. Edward Elgar, London, pp 211-227. https://doi.org/10.4337/9781781000113.00021

Morris JM, Dumble PL, Wigan MR (1979) Accessibility indicators for transport planning. Transp Res Part A Gen 13(2):91-109. https://doi.org/10.1016/0191-2607(79)90012-8

Moya-Gómez B, Salas-Olmedo M, García-Palomares J, Gutiérrez J (2017) Dynamic accessibility using big data: the role of the changing conditions of network congestion and destination attractiveness. Netw Spat Econ. https://doi.org/10.1007/s11067-017-9348-z

München PV (2014) Langfristige Entwicklung der Region München (LaReM). Kommentierte Bestandsaufnahme Daten - Prognosen - Konzepte, München

Páez A, Scott DM, Morency C (2012) Measuring accessibility: positive and normative implementations of various accessibility indicators. J Transp Geogr 25:141-153. https://doi.org/10.1016/j.jtrangeo.2012.03.016

Papa E, Bertolini L (2015) Accessibility and transit-oriented development in European metropolitan areas. J Transp Geogr 47:70-83. https://doi.org/10.1016/j.jtrangeo.2015.07.003

Papa E, Silva C, Te Brömmelstroet M, Hull A (2016) Accessibility instruments for planning practice: a review of European experiences. J Transp Land Use 9:57-75

Pitot M, Yigitcanlar T, Sipe N, Evans R (2006) Land use and public transport accessibility index (LUPTAI) tool: the development and pilot application of LUPTAI for the gold coast. Paper presented at the 29th Australasian research forum

Reggiani A, Bucci P, Russo G (2011b) Accessibility and network structures in the German commuting. Netw Spat Econ 11(4):621-641. https://doi.org/10.1007/s11067-010-9149-0

Reggiani A, Bucci P, Russo G, Haas A, Nijkamp P (2011a) Regional labour markets and job accessibility in City network systems in Germany. J Transp Geogr 19(4):528-536. https://doi.org/10.1016/j.jtrangeo.2010.05.008

Reggiani A, Martín JC (2011) Guest editorial: new Frontiers in accessibility modelling: an introduction. Netw Spat Econ 11(4):577-580. https://doi.org/10.1007/s11067-011-9155-x

Reiss-Schmidt S (2014) Aktuelle Herausforderungen der Münchner Wohnungspolitik. Wohnungsbautagung der Regierung von Oberbayern. In: Conference presentation from 11th July 2014, Munich

Reusser DE, Loukopoulos P, Stauffacher M, Scholz RW (2008) Classifying railway stations for sustainable transitions - balancing node and place functions. J Transp Geogr 16(3):191-202. https://doi.org/10.1016 /j.jtrangeo.2007.05.004

Rose A (2009) Economic resilience to disasters. CARRI research report 8. Community and regional resilience institute, Oak ridge

Sanchez T, Shen Q, Peng Z-r (2004) Transit mobility, jobs access and low-income labour participation in us metropolitan areas. Urban Stud 41(7):1313-1331. https://doi.org/10.1080/0042098042000214815

Sen A (1999) Ökonomie für den Menschen. Wege zur Gerechtigkeit und Solidarität in der Marktwirtschaft. DTV, Munich

te Brömmelstroet MCG, Silva C, Bertolini L (2014) COST action TU1002 - Assessing Usability of Accessibility Instruments. Brussels: COST

te Brömmelstroet M, Skou Nicolaisen M, Büttner B, Ferreira A (2017) Experiences with transportation models: an international survey of planning practices. Transp Policy 58:10-18. https://doi.org/10.1016 j.tranpol.2017.04.007

Turner BL, Kasperson RE, Matson PA, McCarthy JJ, Corell RW, Christensen L, Eckley N, Kasperson J, Luers A, Martello M, Polsky C (2003) A framework for vulnerability analysis in sustainability science. Proc Natl Acad Sci 100(14):8074-8079. https://doi.org/10.1073/pnas.1231335100

van Wee B (2011) Evaluating the impact of land use on travel behaviour: the environment versus accessibility. J Transp Geogr 19(6):1530-1533

Walker J (2012) Human transit: how clearer thinking about public transit can enrich our communities and our lives. Island Press, Washington, DC. https://doi.org/10.5822/978-1-61091-174-0

Wang F (2000) Modeling commuting patterns in Chicago in a GIS environment: a job accessibility perspective. Prof Geogr 52(1):120-133. https://doi.org/10.1111/0033-0124.00210

Warren-Kretzschmar B, Tiedtke S (2005) What role does visualization play in communication with citizens?-a field study from the interactive landscape plan. In: Buhmann E (ed) Trends in real-time landscape visualization and participation. Wichmann Verlag, Heidelberg, pp 156-167

Wegener M, Furst F (1999) Land-use transport interaction: state of the art. Deliverable D2a of the project TRANSLAND. Berichte aus den Insititut fur Raumplanung 46, Universitat Dortmund, Insititut fur Raumplanung, Dortmund 